\title{
Cold Atmospheric Pressure Nitrogen Plasma Jet for Enhancement Germination of Wheat Seeds
}

\author{
Khaled Lotfy ${ }^{1,2} \cdot$ Nadi Awad Al-Harbi ${ }^{1} \cdot$ Hany Abd El-Raheem ${ }^{3}$
}

Received: 21 October 2018 / Accepted: 21 February 2019 / Published online: 2 March 2019

(c) Springer Science+Business Media, LLC, part of Springer Nature 2019

\begin{abstract}
The possibility to improve the germination characterization of the wheat seeds by cold atmospheric nitrogen plasma jet treatment was report. Spectroscopic measurements were performed to identify the constituent particles of a nitrogen atmospheric plasma jet. Spectroscopic measurements revealed that the particles with relatively high energy excited states exist inside the jet nozzle. During this study the cold atmospheric plasma parameters were set for attain the highest rate of the germination seeds. The nitrogen used in this system as carrier gas. The nitrogen cold atmospheric plasma operated at $14 \mathrm{l} / \mathrm{min}$ as a fixed flow rate. The operation of plasma jet at $14 \mathrm{l} / \mathrm{min}$ was represented the suitable plasma dose to enhancement the germination parameters. The $\mathrm{N}_{2}$ first positive system $\left(\mathrm{N}_{2} 1+\right)$, $\mathrm{N}_{2}$ second positive system $\left(\mathrm{N}_{2} 2+\right)$ and $\mathrm{N}_{2}$ ion first negative system $\left(\mathrm{N}_{2}{ }^{+} 1-\right)$ were represented the emission spectra observed inside the jet nozzle. The germination characteristics of wheat seeds have been significantly enhanced after cold atmospheric plasma treatment. The mean weight of fresh sprout was $823.82 \mathrm{mg}$ for untreated seeds and increased to $1231.80,1369.50$ and $1342.46 \mathrm{mg}$ for $2 \mathrm{~min}, 4 \mathrm{~min}$, and 6 min treatments respectively. The effects of nitrogen cold atmospheric plasma jet on the growth parameter depended on exposure time.
\end{abstract}

Keywords Plasma jet $\cdot$ Spectroscopic measurements $\cdot$ Germination rate $\cdot$ Seedling growth

\section{Introduction}

In the last two decades non-equilibrium atmospheric plasma, also known as cold atmospheric plasma (CAP), has undeniably risen an increasingly amount of interest both in the scientific and industrial worlds. While it's potential is still to be fully discovered, its role as one of the leading scientific innovations of the twenty-first century is less and less

Khaled Lotfy

khaledlotfy52@yahoo.com

1 Department of Biology, Faculty of Science, Branch of Tayma, University of Tabuk, Tabuk, Kingdom of Saudi Arabia

2 King Marriott Higher Institute of Engineering \& Technology, Alexandria, Egypt

3 Center for Materials Science, Zewail City of Science and Technology, October Gardens, 6th of October City, Giza, Egypt 
questioned. However, because the facility of non-equilibrium atmospheric plasma devices design as well as their low cost, recently it has been using in many applications. Among the different types of non- plasma, the cold atmospheric plasma jet (CAPJ) represented a promising sort in the treatment of surfaces and living tissues [1-6]. In plasma technology the term plasma jet is used to refer to many different configurations and types of plasmas, having in common that the gas discharge is operated in an open volume electrodes arrangement and plasma is projected outside the electrode arrangement into the environment. The expansion of the plasma is often due to a high flow of a working gas, usually a noble gas, flown through a capillary before expansion into ambient air, where it forms a channel, also named plume, surrounded by air. The important advantages of cold atmospheric plasma jet is the running it in open air because it overcomes the obstacles represented by the use of vacuum-based plasma. An important advantage of CAPJ is the ability to generating certain chemical compounds that can penetrate the treated material surface [7]. Over the past years, the advantages of many CAPJ devices have been studied also the applicability in the medical and biological fields have been investigated [8-16].

Recently, plasma has attracted the attention of many researchers, especially in the field of energy transformations and biological sciences. Plasma treatment can be applied efficiently when controlling plasma parameters such as the appropriate reactive species, Species density, plasma temperature and plasma dose, which can stimulate and accelerate biological processes [17]. As the plasma produced ions, electrons and excited species interact with ambient air, other RONS are generated. The RONS produced in this manner are believed to be the main agents in biomedical applications including atomic oxygen $(\mathrm{O})$, hydroxyl radicals $(\mathrm{OH})$, ozone $\left(\mathrm{O}_{3}\right)$, hydrogen peroxide $\left(\mathrm{H}_{2} \mathrm{O}_{2}\right)$ and nitric oxide (NO) [18].

In the agricultural applications, researchers are interested in the interaction between the reactive species which generated by cold plasma and the seeds, which would improve many properties, including the removal of contamination of seeds [19, 20], water uptake imbibation [20], breaking of dormancy [21], enhancement of seed germination [22-24] and seedling growth [25-29], and draught stress [30]. Cold atmospheric plasma which consisting of electrons, molecules, excited atoms, ionized gases, radicals and strong electric field considered as one of the physical methods for seed treatment. Previous studies have demonstrated that cold plasma treatment could enhance seed germination and seedling growth of many plants including Carthamus tinctorium L., wheat, tomato, soybean [31-33], and watermelon [34].

A hydrophobic and a hydrophilic thin layer can be formed on the surface of the treated material after plasma treatment. This change of the material surface gives positive results with respect to different cultivation conditions and seed types. Volin et al have studied the effect of hydrophobic thin layers on the delaying imbibition in seeds sown in the different types of the soil [35]. it is well known that the seeds with high moisture content can be susceptible to imbibition chilling injury.

So that, the hydrophobic thin layer has a powerful effect on the improving viability in some seeds which occur by reducing water uptake [36-39]. On the other study, by improvement the hydrophilicity of seeds this led to enhancement the water uptake and the seeds germination [29]. Previous studies have shown that plasma has high sterilization efficiency for seeds and preserved foods because of the inactivation occur for many microorganisms through this method [40, 41]. The effect of cold atmospheric plasma on various food contaminant microorganisms such as, A. flavus, Staphylococcus aureus, Fusarium spp., Saccharomyces cerevisiae, Candida albicans, Aspergillus niger, Escherichia coli, Bacillus subtilis and other microorganisms have been studied on different materials [42-44]. Plasma used to inactivation of many food contaminant microorganisms like, Fusarium spp., A. 
flavus, Aspergillus niger, Candida albicans, Saccharomyces cerevisiae, Staphylococcus aureus, Bacillus subtilis, Escherichia coli, and other microorganisms have been studied on different materials [42-44].

Wheat is the essential strategic crop for one-third of the world's population [45]. As for Egypt, it is considered as the first strategic crop as it represents the significant part of the Egyptian diet. Currently, there is a significant insufficiency of wheat production in Egypt, which leads to the import of a large proportion to overcome for this shortfall in production [46]. Because of the continuous increase in the population in Egypt, so we must find the appropriate ways to increase the production of wheat to overcome the extreme demand for food. The food needs of Egypt's population can be met by increasing seed germination rate as well as wheat plant growth. Recently we designed and constructed a nitrogen-plasma jet device designed; the device operated using a commercially neon power supply [16]. In this study, we focused on exploring the feasibility of nitrogen cold atmospheric plasma jet (NCAPJ) on seeds germination and seedling growth of wheat. The authors also investigate the optimization of the operating conditions in cold atmospheric plasma to increase the percentage germination and total vigor of seedlings.

\section{Materials and Methods}

\section{Characteristics of Plasma Source}

In the current study the NCAPJ system was used in the treatment of wheat seeds. As can be seen in Fig. 1, the design of the NCAPJ was described in an earlier study [13]. The highvoltage power supply is a commercially available transformer for neon light. The neon power supply is appropriated in the cold atmospheric plasma to produce the plasma jet to cut the overall cost of the system by substituting the expensive RF power supply representing the major cost. The output of the high-voltage neon power supply is $30 \mathrm{~mA}, 10 \mathrm{kV}$, and $20 \mathrm{kHz}$ which lie in the range of very depressed frequency of RF. This power supply has an overload, open circuit, earth leakage and short circuit protection. The input of this power supply is connected to $220 \mathrm{~V}, 12$ A voltage controller. The voltage controller regulates the primary voltage of the high-voltage transformer. The electrode system of the NCAPJ made

Fig. 1 The electric circuit of cold atmospheric plasma jet device, (1) input electric source $220 \mathrm{~V}$, (2) voltage controllers, (3) neon power supply, (4) gas feeding through copper tube, (5) anode, (6) cathode, (7) plasma jet and (8) acrylic box. Attached photo display the NCAPJ system

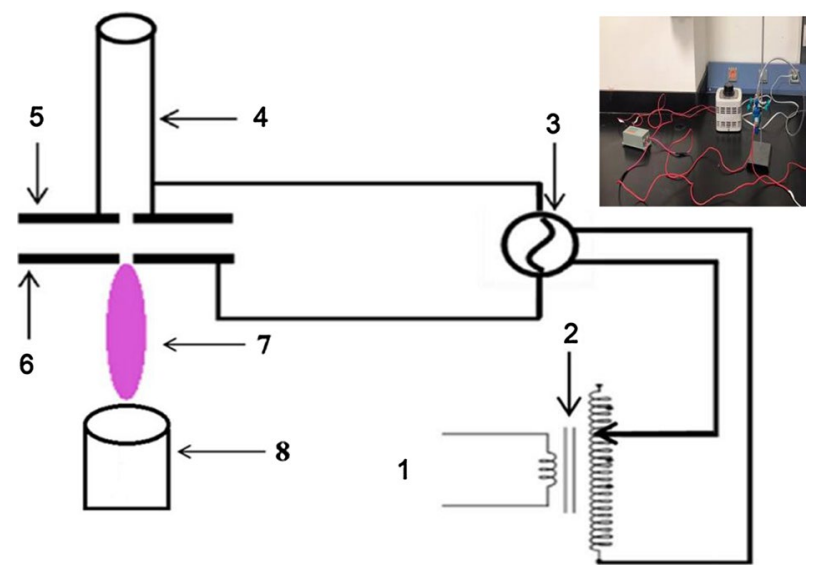


up of two parallel stainless steel disks detached by Teflon insulator. The external electrode and the inside electrode have represented the cathode, and the anode respectively. However, the cathode and the anode have similar thickness and diameter $15 \mathrm{~mm}$ and $2 \mathrm{~mm}$ respectively, but the Teflon disk has a $1 \mathrm{~mm}$ thickness and $15 \mathrm{~mm}$ in diameter. The two electrodes and Teflon disk have center hole of $1 \mathrm{~mm}$ and $1.2 \mathrm{~mm}$ diameter respectively, through center hole nitrogen gas is flowing. The gas flow system is liable for transporting the gas to the plasma jet at the convenient flow-rate. It composed of the gas storage cylinder, binary-stage gas flow controller, and gas connection rubber hose. The Nitrogen was used in this work as a carrier gas. Once the nitrogen gas introduced through the two electrodes and the suitable high voltage applied between them, the nitrogen atoms are ionized by driving off electrons so that, the ionization of neighboring nitrogen species occurred by a collision with free electrons. After the series of these reactions the nitrogen gas converts to the plasma state.

\section{Emission Spectrum and Discharge Voltage Measurements}

An optical emission spectrometer detects photon emission in this region. Spectra obtained provide valuable information about species present within the plasma and their electron excitation, which in turn enables the calculation of vibrational and electron temperature within the plasma. The UV-visible emission spectra from the plasma reactor were obtained with a spectrometer which consists of a lens connected to a detector via fiber optic cable. In this work, the spectroscopy with the model number of HR4000CG-UV-NIR (Ocean Optics) was employed. However, the voltage measurement was performed using a highvoltage probe P6015 Tektronix HV probe and the currents by a TCP202 Tektronix current probe with a digital oscilloscope (Tektronix MSO4032).

\section{Plant Material}

The Giza 168 seeds one of the bread wheat cultivars were obtained from a private company. Healthy wheat seeds were selected and stored in plastic containers under the conditions of our laboratory at $50 \%$ relative humidity and temperature $24-25^{\circ} \mathrm{C}$.

\section{Seeds Treatment}

The plasma jet ejected to the acrylic box which contains wheat seeds. The wheat seeds were distributed regularly and then subjected to plasma radiation for different periods of time 2 , 4, 6, 8 and $10 \mathrm{~min}$. The distance between the nozzle of plasma jet and wheat seeds was fixed at $1.7 \mathrm{~mm}$. In each treatment, 20 wheat seeds were unilaminar spread flat out on the bottom of the acrylic box; all procedures had been repeated four times. When the nitrogen flow rate was adjusted at $141 / \mathrm{min}$ and the $2.6 \mathrm{kV}$ is the applied voltage, then the plasma jet generated between the two electrodes and ejected to the acrylic box. In this experimental, the length and the diameter of the plasma plume were $7 \mathrm{~mm}$ and $3 \mathrm{~mm}$ respectively, as can be seen in Fig. 2. The spatial uniformity of the plasma jet has been obtained at these conditions of the current system as can be seen in Fig. 2. However, the plasma temperature is one the most necessary parameters in biomedical applications attributable to the sensitivity of living cells and their inner organs like proteins. The plasma temperature should stay below an exact quantity of degree. During this method, plasma won't have any thermal effects like ablation or clotting. A 
Fig. 2 Nitrogen cold atmospheric plasma plume

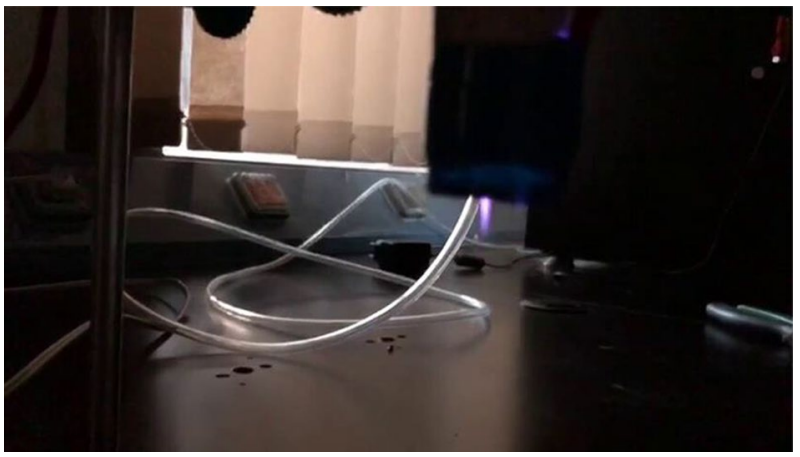

thermocouple was used to measure the plasma temperature. The gas temperature was varied from 25.5 to $31{ }^{\circ} \mathrm{C}$ when the period time of plasma radiation changes from 2 to $10 \mathrm{~min}$.

One way ANOVA was used to analysis the obtained data and the comparisons with $P<0.05$ were considered significantly different. On the other hand, to measure the temperature of seeds through plasma treatment A GM1150 Infra-Red thermometer has been used. This thermometer has a measuring temperature range from -50 to $1150{ }^{\circ} \mathrm{C}$.

Infrared thermometers measure the energy emitted by the surface focused onto the detector instead of surface temperature as such. The IRT detector is filtered to allow only a specific waveband, typically 8 to $14 \mathrm{~km}$, onto the detector. This captured energy, E, is converted to temperature (T) via Stefan's Law, which states

$$
E=\varepsilon \sigma T^{4}
$$

where $\varepsilon$ is the emissivity of the object and $\sigma$ the Stefan-Boltzman constant $\left(5.68 \times 10^{-8} \mathrm{~J} \mathrm{~m}^{-2} \mathrm{~s}^{-1} \mathrm{~K}^{-4}\right)$. Emissivity can be thought of as an "emittance efficiency factor"; Most plants have emissivity of 0.97 to 0.99 [47].

The wettability of treated and untreated seeds was calculated using the following equation:

$$
\text { wettability }=\frac{m_{1}-m_{0}}{m_{0}}
$$

where $\mathrm{m}_{0}$ represent the mass of seeds before soaked in water, and $\mathrm{m}_{1}$ represent the mass of seeds after soaked in water. However, in current study the seeds were soaked for $12 \mathrm{~h}$ and weighted each $2 \mathrm{~h}$ after immersion in water.

Seeds were transferred to a transparent plastic cup containing one layer of filter paper, each cup contained twenty seeds. The Seeds germination process was took place in the dark at room temperature. The seeds germination process was observed for the duration of 10 days.

The following equations were used to calculate the germination characteristics of treated and untreated seeds [35].

After $24 \mathrm{~h}$ of cultivation, the germination potential was calculated using the following equation:

$$
\text { Germination potential } \%=\frac{\text { Number of seeds germinated after } 1 \text { day }}{\text { Total number of seeds }} \times 100 .
$$

However, the germination rate calculated after 4 days of cultivation from the following equation.

$$
\text { Germination rate } \%=\frac{\text { Number of seeds germinated after } 4 \text { days }}{\text { Total number of seeds }} \times 100 \text {. }
$$


Finally, the final germination percentage was calculated using the following equation after 10 days:

Final germination percentage $\%=\frac{\text { Number of germinated seeds after } 10 \text { days }}{\text { Total number of seeds }} \times 100$

\section{Seedling Characteristics}

After 10 days the seedlings were collected from all samples and shoot length was evaluated as the length of the seedling from the seed to the tip of the leaf blade. On the other hand the root length was evaluated as the length of the seedling from the seed to the tip of the root. Shoot and root fresh weight was evaluated as the weight of seedling shoot and root respectively, and expressed in milligram. However, Shoot and root dry weight was evaluated as the weight of seedling shoot and root after oven drying at $90{ }^{\circ} \mathrm{c}$ for $48 \mathrm{~h}$ respectively, and expressed in milligram. Moreover the following equations were used to evaluate the seed vigor I and II [36]:

$$
\begin{aligned}
& \text { Vigor index } I=\frac{\text { fresh seedling weight in } \mathrm{mg} \times \text { germination percentage }}{100} \\
& \text { Vigor index } I I=\frac{\text { dry seedling weight in } \mathrm{mg} \times \text { germination percentage }}{100} .
\end{aligned}
$$

\section{Result and Discussion}

\section{Seeds Temperature Measurement}

Figure 3 shows the wheat seeds temperature through nitrogen plasma jet treatment using infra-red thermometer. From this figure, it can be showed that, by increasing the exposure time of plasma jet the temperature increase continuously. At $2 \mathrm{~min}$ of the operation time, the seeds temperature closed to room temperature $\left(25.8^{\circ} \mathrm{C}\right)$. Even the operation time reaches $10 \mathrm{~min}$; the seeds temperature is as low as $29.5^{\circ} \mathrm{C}$. It means that, cold atmospheric plasma jet present a suitable method to enhancement germination without harmful effects.

\section{Emission Spectrum and Discharge Voltage Measurements}

Figure 4 shows the volt-ampere waveform of produced nitrogen plasma measured at $14 \mathrm{l} /$ min as nitrogen flow rate. It can be seen from this figure that, the values of discharge voltage and discharge current is $2.6 \mathrm{kV}$ and $38.1 \mathrm{~mA}$ respectively. However, the long plume plasma jet was observed by Ocean optical emission spectroscopy to investigate the behavior of atomic and molecular nitrogen and other constituent species. However nitrogen plasma emits high amounts of reactive species [48] so that; it used as a carrier gas in this experiment. The spectrum of the nitrogen plasma jet at flow rate of $14 \mathrm{l} / \mathrm{m}$ was showed in Figs. 5 and 6 from 200 to $500 \mathrm{~nm}$ and 600 to $900 \mathrm{~nm}$ respectively. The $\mathrm{N}_{2}$ first positive system $\left(\mathrm{N}_{2} 1+\right), \mathrm{N}_{2}$ second positive system $\left(\mathrm{N}_{2} 2+\right)$ and $\mathrm{N}_{2}$ ion first negative system $\left(\mathrm{N}_{2}{ }^{+}{ }^{-}-\right)$ were represented the emission spectra observed inside the jet nozzle. The emission lines in Fig. 5 were primarily dominated by $N_{2}$ second positive system $\left(C^{3} \Pi_{u}-B^{3} \sum_{g}\right)$ and $N_{2}$ 
Fig. 3 The temperature of wheat seeds after plasma treatment

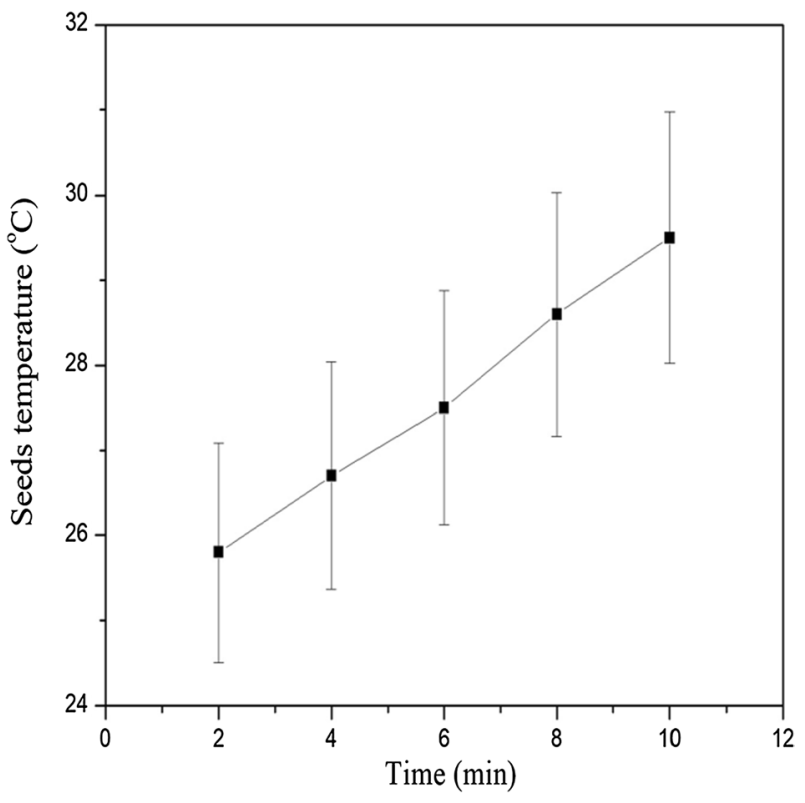

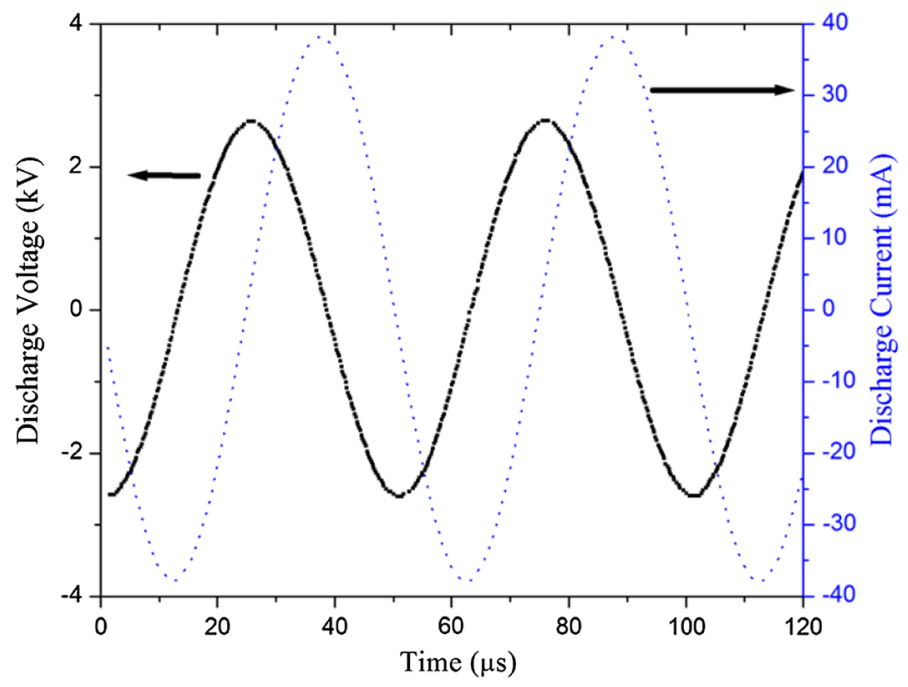

Fig. 4 The discharge voltage and discharge current at 14 1/min as a fixed flow rate

ion first negative system $\left(\mathrm{B}^{2} \sum_{\mathrm{u}}-\mathrm{X}^{2} \sum_{\mathrm{g}}^{+}\right)$. The characteristic spectrum of the second positive system transitions is shown at 339.1 and $359.4 \mathrm{~nm}$, while the nitrogen first negative system transitions is shown at $392.9 \mathrm{~nm}$. The emission lines as can be seen in Fig. 6 were primarily dominated by the reactive species related oxygen $\left(\mathrm{O} \mathrm{I}{ }^{5} \mathrm{~S}^{0}{ }_{-}^{5} \mathrm{P}\right)$ at $6.18 .5 \mathrm{~nm}$. On the other hand, another reactive atomic oxygen has been detected at 777.7 and $843.3 \mathrm{~nm}$ [49, 50]. Additionally, the reactive atomic nitrogen has been detected at 744.6, and 
Fig. 5 Emission spectra from 200-500 nm observed inside the jet nozzle at $14 \mathrm{l} / \mathrm{min}$ as a fixed flow rate respectively
Fig. 6 Emission spectra from 600 to $900 \mathrm{~nm}$ observed inside the jet nozzle at $14 \mathrm{l} / \mathrm{min}$ as a fixed flow rate
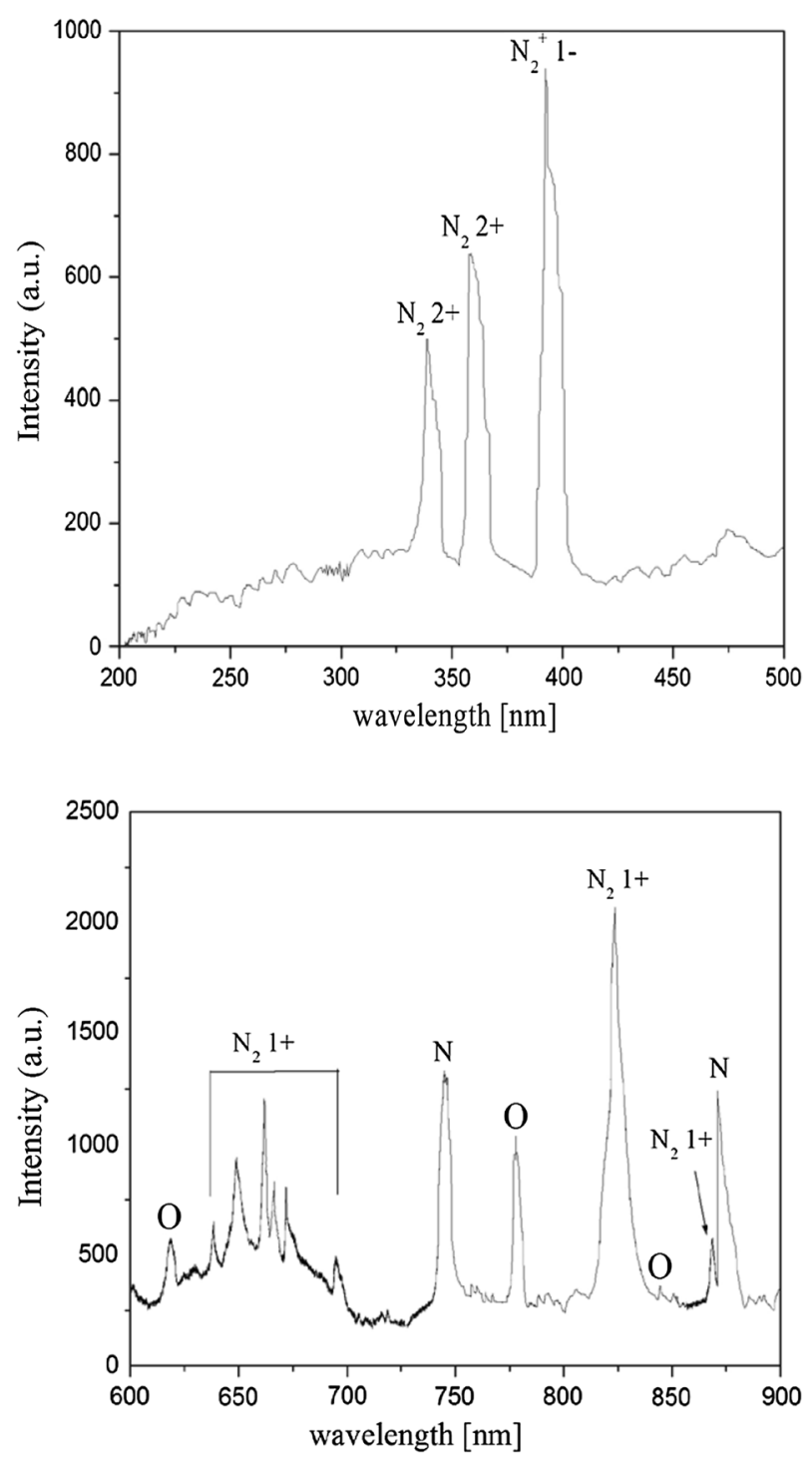

$870.8 \mathrm{~nm}[49,51]$. Another reactive spice has been detected is nitrogen first positive system $\left(B^{3} \Pi_{\mathrm{g}}-\mathrm{A}^{3} \sum_{\mathrm{u}}^{+}\right)$, these transitions are shown in the range of 639.1-695.02 $\mathrm{nm}$ and also detected in 824.6 and $867.3 \mathrm{~nm}$.

\section{Wettability Measurements}

No doubt that, the seed coat of plants may hinder their ability to absorb water, which has a dramatic effect on the process of seed germination [52]. On the other hand, Yiran et al. (2017) observed that the morphology of the wheat seed coat was changed after plasma treatments; it has been led to enhancement of the water uptake and promotion of wheat 
seed germination was occurred [53]. From Table 1, it can be noticed that the mean wettability after $2 \mathrm{~h}$ was $19.12 \%$ for the controlled seeds but increased to $24.21 \%, 35.58 \%$, $25.72 \%, 27.67 \%$ and $26.38 \%$ for the $\mathrm{X}_{2}, \mathrm{X}_{4}, \mathrm{X}_{6}, \mathrm{X}_{8}$ and $\mathrm{X}_{10}$ treatments respectively. On the other hand, it can observe that the wettability of $\mathrm{X}_{2}, \mathrm{X}_{4}, \mathrm{X}_{6}, \mathrm{X}_{8}$ and $\mathrm{X}_{10}$ treatments exhibit significant differences compared with the control seeds. However, there are no significant differences between the wettability of $\mathrm{X}_{2}, \mathrm{X}_{6}, \mathrm{X}_{8}$ and $\mathrm{X}_{10}$ treatments. The results show that, the wettability of wheat seeds treated by cold atmospheric plasma jet increased with respect to untreated one. From these data, it can be noticed that, the nitrogen cold atmospheric plasma has a positive effect on the wettability of wheat seeds. However, there is a significant difference between treated and untreated wheat seeds after soaked in water for $4,6,8$ and $10 \mathrm{~h}$, While, there is no a significant difference between $\mathrm{X}_{2}, \mathrm{X}_{4}, \mathrm{X}_{6}, \mathrm{X}_{8}$ and $\mathrm{X}_{10}$ plasma treatments. From these results it can notice that, the treated seeds reached water- saturation faster untreated seeds because the wettability dynamic of treated seeds plasma decrease by increasing imbibition time. After soaked in water for $12 \mathrm{~h}$ there is no significant differences between all samples because the seeds were reached water- saturation in all variants [44, 52].Numerous studies have suggested that there might be some association between seed germination and water uptake, and the water uptake of seeds would benefit seed germination and seedling growth [35, 52]. In current work it can be found that nitrogen cold atmospheric plasma treatments enhanced the water uptake of wheat seed, and these results were consistent with the findings of Filatova et al. [54] and Bormashenko et al [29]. Filatova et al observed that the cold plasma treatment could improve the water uptake of some grains and legumes. Bormashenko et al. observed that the water uptake of oat was enhanced after RF plasma treatment. However, the wetting properties of seeds were altered due to oxidation of the seed surface by the plasma treatment, which would then improve water uptake and seed germination [29]. On the other hand, the wetting properties of oat and wheat seeds were improved after microwave plasma treatment, as well as their germination [32]. Moreover, the plasma treatment of seeds can be led to the change of the surface roughness and the chemical structure of grain and so that the shift of wetting characteristics has been occurred as well as affected its water uptake [55]. The enhancement of seeds ability to absorb water can be attributed to the improvement of the seeds hydrophilic by plasma treatment. However, the seeds ability to absorb water could be enhanced as well as the germination growth [22].

Table 1 Evolution of water uptake of the wheat seeds with CAPJ plasma treatment time, lowercase letters a-d in the same column represent significance analysis; the different letters mean significant difference among various treatments at $P<0.05$ level

\begin{tabular}{|c|c|c|c|c|c|c|}
\hline \multirow{2}{*}{$\begin{array}{l}\text { Plasma } \\
\text { treatment } \\
(\mathrm{min})\end{array}$} & \multicolumn{6}{|l|}{ Imbibition time } \\
\hline & $2 \mathrm{~h}$ & $4 \mathrm{~h}$ & $6 \mathrm{~h}$ & $8 \mathrm{~h}$ & $10 \mathrm{~h}$ & $12 \mathrm{~h}$ \\
\hline $0\left(\mathrm{X}_{0}\right)$ & $19.12 \pm 0.63 a$ & $41.41 \pm 0.74 a$ & $55.38 \pm 1.23 \mathrm{a}$ & $58.89 \pm 0.60 \mathrm{a}$ & $70.81 \pm 0.50 \mathrm{a}$ & $81.20 \pm 0.60 \mathrm{a}$ \\
\hline $2\left(X_{2}\right)$ & $24.21 \pm 1.09 c$ & $48.21 \pm 1.02 c$ & $62.19 \pm 1.06 \mathrm{c}$ & $63.74 \pm 0.59 c$ & $80.26 \pm 0.95 b$ & $82.28 \pm 0.92 \mathrm{a}$ \\
\hline $4\left(X_{4}\right)$ & $35.58 \pm 1.37 \mathrm{~b}$ & $58.88 \pm 0.55 b$ & $68.18 \pm 1.01 \mathrm{~b}$ & $80.14 \pm 1.09 b$ & $82.17 \pm 0.79 b$ & $83.98 \pm 0.23 a$ \\
\hline $6\left(X_{6}\right)$ & $25.72 \pm 0.74 \mathrm{~cd}$ & $48.27 \pm 0.92 c$ & $62.01 \pm 0.66 c$ & $72.88 \pm 0.63 c$ & $81.22 \pm 0.01 b$ & $83.25 \pm 0.33 a$ \\
\hline $8\left(\mathrm{X}_{8}\right)$ & $27.67 \pm 0.51 d$ & $48.31 \pm 1.08 \mathrm{c}$ & $64.74 \pm 0.60 c$ & $75.03 \pm 0.35 c$ & $80.64 \pm 0.37 b$ & $81.08 \pm 0.28 \mathrm{a}$ \\
\hline $10\left(\mathrm{X}_{10}\right)$ & $26.38 \pm 0.16 \mathrm{~cd}$ & $48.55 \pm 0.60 \mathrm{c}$ & $64.25 \pm 0.97 \mathrm{c}$ & $74.13 \pm 0.50 \mathrm{c}$ & $80.22 \pm 0.89 b$ & $80.93 \pm 0.49 a$ \\
\hline
\end{tabular}




\section{Germination Characteristics}

Seed dormancy is an intrinsic seed characteristic that allows the species to reproduce generatively to survive [56]. Non-thermal plasma is considered a novel stimulation treatment to break down dormancy [57]. Plasma treatment could generate UV radiation, radicals, and chemical reactions, which played a significant role in dormancy breaking. Non-thermal helium plasma might operate in dormancy breaking [58]. The germination results of untreated and treated wheat seeds after nitrogen cold atmospheric plasma jet were shown in Table 2. After one day of the plant, the mean germination potential was $21.4 \%$ in the untreated seeds, and it significantly increased to $91.3 \%$ in the $\mathrm{X}_{4}$ treatment. Because the significant differences of the germination potential between treated and control seeds, it can be conclude that, the nitrogen cold atmospheric plasma enhancement the germination potential of wheat seeds. However, the $\mathrm{X}_{6}, \mathrm{X}_{8}$ and $\mathrm{X}_{10}$ treatments exhibit no significant difference between them. Also the nitrogen cold atmospheric plasma jet could improve the germination rate and germination percentage. In the case of germination rate, as can be seen in Fig. 7, 49.8\% was obtained in untreated seeds, and it enhanced to $93.3 \%$ in $X_{4}$ treatment, and further increasing the treatment time did not improve the germination rate, because the difference among $\mathrm{X}_{6}, \mathrm{X}_{8}$ and $\mathrm{X}_{10}$ treatments was not significant. Moreover, the germination percentage increased from $67.9 \%$ in control seeds to $97.4 \%$ in the $\mathrm{X}_{4}$ treatment. On the other hand, there was no significant difference among $\mathrm{X}_{6}, \mathrm{X}_{8}$ and $\mathrm{X}_{10}$ treatments. These results indicated that, the germination potential, germination rate and germination percentage for NCAPJ exhibited significant difference compared with untreated one. The highest mean germination potential, germination rate and germination percentage were obtained in the $\mathrm{X}_{4}$ treatment. So that, we can conclude that, the enhancement of the wheat seeds germination depends on the cold atmospheric plasma dose, these results are consistent with the results obtained by Li et al. [33]. It is illustrated that the reactive oxygen and nitrogen species (RONS) are the essential signaling molecules organizing many growth processes in mammalian, microorganisms, and plants. The dose value of RONS can play an essential role in the control of growth and improvement of plants [59].

\section{Seedling Growth at Different Plasma Dose}

Table 3 displays the effects of NCAPJ treatment on the seedling growth of the wheat seeds. The mean root length was $1234.16,1358.50,1596.83$ and $1375.40 \mathrm{~mm}$ for the control

Table 2 Effect of CAPJ plasma treatment time on the Germination characteristics for wheat seeds germination, lowercase letters $\mathrm{a}-\mathrm{f}$ in the same column represent significance analysis; the different letters mean significant difference among various treatments at $P<0.05$ level

\begin{tabular}{llll}
\hline Treatment time $(\mathrm{min})$ & Germination potential $\%$ & Germination rate $\%$ & $\begin{array}{l}\text { Germination } \\
\text { percentage } \%\end{array}$ \\
\hline $0\left(\mathrm{X}_{0}\right)$ & $21.4 \pm 1.0 \mathrm{a}$ & $49.8 \pm 1.3 \mathrm{a}$ & $67.9 \pm 1.4 \mathrm{a}$ \\
$2\left(\mathrm{X}_{2}\right)$ & $75.4 \pm 1.0 \mathrm{~b}$ & $75.7 \pm 2.5 \mathrm{~b}$ & $84.6 \pm 1.6 \mathrm{~b}$ \\
$4\left(\mathrm{X}_{4}\right)$ & $91.3 \pm 1.1 \mathrm{c}$ & $93.3 \pm 1.8 \mathrm{c}$ & $97.4 \pm 1.1 \mathrm{~d}$ \\
$6\left(\mathrm{X}_{6}\right)$ & $61.6 \pm 1.3 \mathrm{~d}$ & $74.3 \pm 1.9 \mathrm{~b}$ & $89.3 \pm 0.9 \mathrm{c}$ \\
$8\left(\mathrm{X}_{8}\right)$ & $56.4 \pm 1.1 \mathrm{de}$ & $72.2 \pm 2.5 \mathrm{~b}$ & $80.2 \pm 0.9 \mathrm{~b}$ \\
$10\left(\mathrm{X}_{10}\right)$ & $65.2 \pm 2.0 \mathrm{df}$ & $80.5 \pm 1.6 \mathrm{bd}$ & $90.3 \pm 1.1 \mathrm{c}$ \\
\hline
\end{tabular}



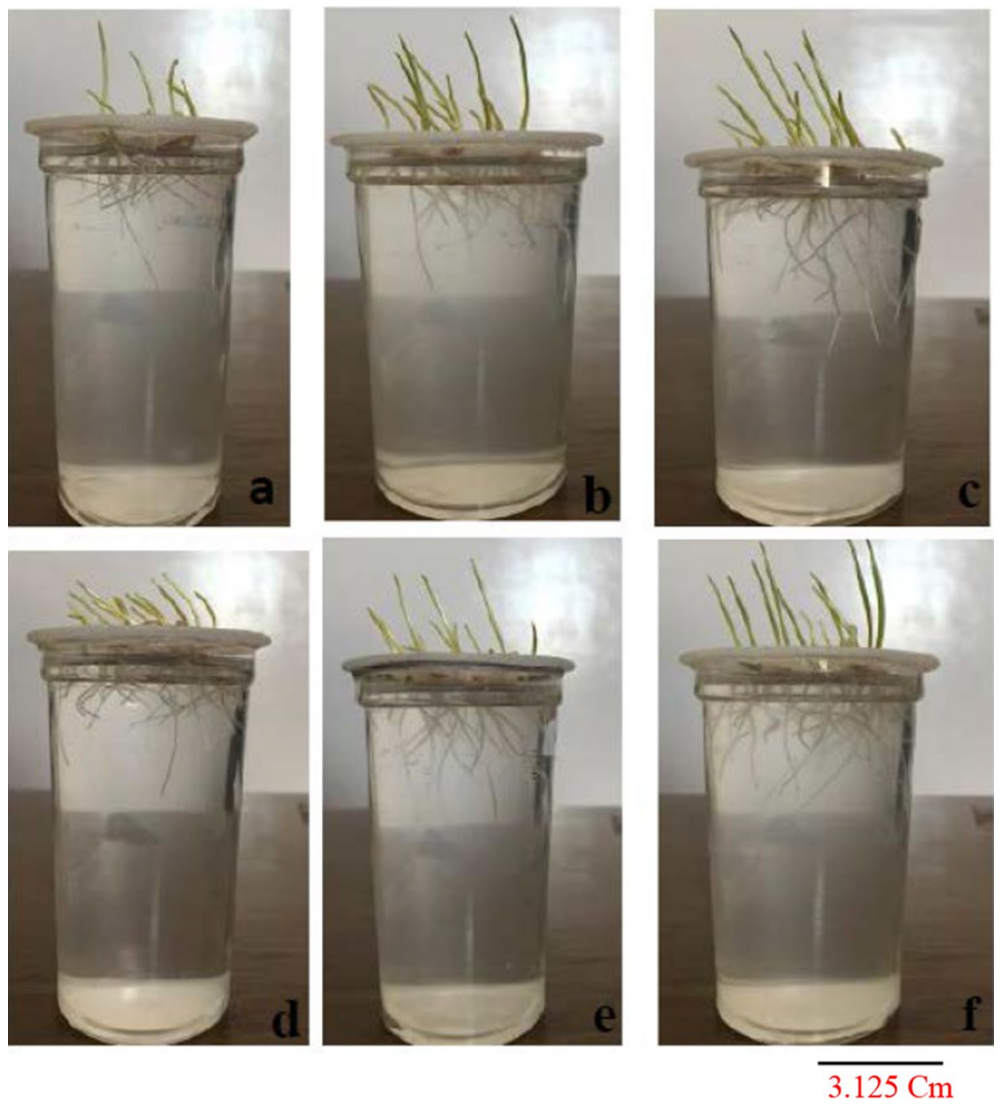

Fig. 7 The treated and untreated Wheat seeds after 4 days of cultivation; a untreated; b 2 min irradiated; $\mathbf{c}$ 4 min irradiated; $\mathbf{d} 6 \mathrm{~min}$ irradiated; e 8 min irradiated and $\mathbf{f} 10 \mathrm{~min}$ irradiated

seeds, $\mathrm{X}_{2}, \mathrm{X}_{4}$ and $\mathrm{X}_{8}$ treatments, respectively, and the difference among these treatments was significant. However, the highest mean root length was obtained in the $\mathrm{X}_{4}$ treatment. On the other hand, the significant difference between $\mathrm{X}_{6}$ and $\mathrm{X}_{10}$ not exist. The mean shoot length increased to $473.30,544.10,504.70,493.43$ and $491.33 \mathrm{~mm}$ for the $\mathrm{X}_{2}, \mathrm{X}_{4}, \mathrm{X}_{6}$, $\mathrm{X}_{8}$ and $\mathrm{X}_{10}$ treatments, respectively, and these treatments presented significant differences compared with the control seeds (the mean shoot length was $357.03 \mathrm{~mm}$ ). Moreover, a significant difference can be observed between $\mathrm{T}_{4}$ treatment which represents the highest mean shoot length and the rest treatments. However, the mean shoot length of $X_{6}, X_{8}$ and $\mathrm{X}_{10}$ treatments do not exhibit significant difference. The mean fresh weight of the seedlings for the $\mathrm{X}_{2}, \mathrm{X}_{4}, \mathrm{X}_{6} \mathrm{X}_{8}$ and $\mathrm{X}_{10}$ treatments were 1766.30, 1985.76, 1855.03,1795.33 and $1797.24 \mathrm{mg}$, respectively, which was $56.9,76.5,64.9,59.5$ and $59.7 \%$ higher than that of the untreated seeds, respectively. From these results, it can conclude that it can be noticed that, the mean fresh weight of treated seeds represents a significant difference with the control one, while the mean fresh weight of $\mathrm{X}_{8}$ and $\mathrm{X}_{10}$ treatments do not exhibit significant difference. Moreover, the highest mean fresh weight was obtained in the case of the $\mathrm{X}_{4}$ treatment. On the other hand, the mean dry weight was $567.34 \mathrm{mg}$ in the untreated seeds and increased to $783.53,875.72,823.72,765.72$ and $764.30 \mathrm{mg}$ for the $\mathrm{X}_{2}, \mathrm{X}_{4}, \mathrm{X}_{6}, \mathrm{X}_{8}$ and 
Table 3 Seedling growth obtained from the control and plasmas treated wheat seeds lowercase letters a-e in the same column represent significance analysis; the different letters mean significant difference among various treatments at $P<0.05$ level

\begin{tabular}{lllll}
\hline Treatment time $(\mathrm{min})$ & Root length $(\mathrm{mm})$ & Shoot length $(\mathrm{mm})$ & Fresh weight $(\mathrm{mg})$ & Dry weight $(\mathrm{mg})$ \\
\hline $0\left(\mathrm{X}_{0}\right)$ & $1234.16 \mathrm{a}$ & $357.03 \pm 2.59 \mathrm{a}$ & $1125.10 \pm 2.20 \mathrm{a}$ & $567.34 \pm 0.20 \mathrm{a}$ \\
$2\left(\mathrm{X}_{2}\right)$ & $1358.50 \mathrm{~b}$ & $473.30 \pm 2.57 \mathrm{~b}$ & $1766.30 \pm 2.07 \mathrm{~b}$ & $783.53 \pm 0.01 \mathrm{~b}$ \\
$4\left(\mathrm{X}_{4}\right)$ & $1596.83 \mathrm{c}$ & $544.10 \pm 2.35 \mathrm{c}$ & $1985.76 \pm 3.94 \mathrm{c}$ & $875.72 \pm 0.55 \mathrm{c}$ \\
$6\left(\mathrm{X}_{6}\right)$ & $1431.03 \mathrm{~d}$ & $504.70 \pm 1.41 \mathrm{e}$ & $1855.03 \pm 1.90 \mathrm{~d}$ & $823.24 \pm 0.03 \mathrm{~d}$ \\
$8\left(\mathrm{X}_{8}\right)$ & $1375.40 \mathrm{e}$ & $493.43 \pm 0.90 \mathrm{e}$ & $1795.33 \pm 0.20 \mathrm{e}$ & $765.72 \pm 0.24 \mathrm{e}$ \\
$10\left(\mathrm{X}_{10}\right)$ & $1457.56 \mathrm{~d}$ & $491.33 \pm 1.15 \mathrm{e}$ & $1797.24 \pm 0.03 \mathrm{e}$ & $764.30 \pm 0.87 \mathrm{e}$ \\
\hline
\end{tabular}

$\mathrm{X}_{10}$ treatments, respectively. However, it can be observed that the mean fresh weight of treated seeds exhibited significant differences compared with the untreated seeds. However, the mean dry weight of $\mathrm{X}_{8}$ and $\mathrm{X}_{10}$ treatment do not exhibit significant difference. The highest mean dry weight was obtained in the $X_{4}$ treatment which was $54.3 \%$ higher than that of the untreated seeds. Moreover, the effects of cold plasma treatment on seed germination and seedling growth of soybean have been studied by Li Let al. The authors improved that the higher and lower energy level doesn't enhancement the seedling growth of soybean, but the enhancement occurs moderate energy [33]. The previous studies proved that the seedling growth of plants had been promoted by cold plasma treatment; the cold plasma treatment was enhanced the seedling growth of Carthamus tinctorius L. [60]; tomato [61]; wheat and oat [32], watermelon [34]. Moreover, [33, 62] have demonstrated that the seeds germination significantly increased by non-thermal plasma treatment.

\section{Vigor Index}

The seed vigor I and II were calculated as can be seen in Table 4 using equation No 5 and 6 respectively. From this table, the mean vigor index I was 1131.77 in the untreated seeds, and it increased to 1985.76 in the $\mathrm{X}_{4}$ treatment. From these result it can notice that, the mean vigor index I between the treated seeds and the control seeds exhibit a significant difference. Also the difference among $\mathrm{X}_{2}, \mathrm{X}_{4}$ and $\mathrm{X}_{6}$ treatments was significant, while there no significant differences between $T_{8}$ and $T_{10}$ treatments. On the other hand, the $\mathrm{X}_{4}$ treatment represents the higher vigor index II compared the rest treatments. However, the mean vigor index II was 382.84 in the untreated seeds, and it increased to 854 in the $\mathrm{T}_{4}$ treatment. Moreover, the vigor index II of treated and

Table 4 Effect of CAPJ on vigor index, different lowercase letters mean significant difference among different treatments at $P<0.05$ level

\begin{tabular}{lll}
\hline Treatment time $(\mathrm{min})$ & Vigor index I & Vigor index II \\
\hline $0\left(\mathrm{X}_{0}\right)$ & $1131.77 \pm 1.02 \mathrm{a}$ & $382.84 \pm 2.38 \mathrm{a}$ \\
$2\left(\mathrm{X}_{2}\right)$ & $1752.30 \pm 2.50 \mathrm{~b}$ & $662.29 \pm 1.12 \mathrm{~b}$ \\
$4\left(\mathrm{X}_{4}\right)$ & $1985.76 \pm 0.25 \mathrm{c}$ & $854.00 \pm 0.99 \mathrm{c}$ \\
$6\left(\mathrm{X}_{6}\right)$ & $1845.03 \pm 1.23 \mathrm{~d}$ & $736.12 \pm 0.81 \mathrm{~d}$ \\
$8\left(\mathrm{X}_{8}\right)$ & $1785.33 \pm 1.05 \mathrm{e}$ & $615.13 \pm 0.79 \mathrm{e}$ \\
$10\left(\mathrm{X}_{10}\right)$ & $1787.24 \pm 1.08 \mathrm{e}$ & $691.82 \pm 1.27 \mathrm{f}$ \\
\hline
\end{tabular}


untreated seeds exhibit a significant difference. Also the difference among treated seeds was significant. Lotfy concluded that the improvement of the vigor indexes of treated seeds can be attributed to the higher root and shoot length of treated seeds compared to untreated one [34]. From these results, it can concluded that the improvement of wheat vigor seeds which occurred by NCAPJ will be produced a high-quality yield in agricultural production. So that, NCAPJ treatment can be used to improve the vigor index in laboratory conditions. The last studies revealed that plasma-induced effects on the seed surface could produce to the permeation of RONS and UV inside seeds, which in all likelihood influence the physiological response, the seed germination, and the growth of plants $[63,64]$. Therefore, from this work, it can be decided that the NCAPJ treatment of wheat seeds not only displayed a short term impact on the rate germination but also manifested a long term influence on the stem and the root growths.

\section{Sprouts Weight}

From Table 5 the mean weight of fresh sprout was 823.82, 1231.80, 1369.50 and $1342.46 \mathrm{mg}$ for the control, $\mathrm{X}_{2}, \mathrm{X}_{4}$, and $\mathrm{X}_{6}$ treatments, respectively, the difference among these treatments was significant, and the highest mean root length was obtained in the $\mathrm{T}_{4}$ treatment. On the other hand, there is no a significant difference among $\mathrm{X}_{8}$ and $\mathrm{X}_{10}$ treatments. The same behavior was observed for the weight of dry spout. From these data, it could be observed that, the treated wheat seeds had a greater sprouts weight compared control one. From these results, it can be concluded that, the NCAPJ has a promise effect on germination improvement. Previous research showed that the dry mas of radish sprouts which treated with non-thermal plasma recorded higher value with concerning untreated one [65].

However, Krentsel et al. assumed that either of two processes or both accomplish the impact of the plasma treatment on seeds; that is, (1) a direct treatment on the seed coat and (2) an effect on the cells inside the seed. The direct treatment on the seed coat resulted in the etching influences by reactive spices and UV irradiation. On the other hand, the influence on the cells within the seed included the permeation of reactive spices. [66]. Sera et al. found that the contents of phenolic molecules in wheat and oat seeds modified after plasma treatment, and they ascribed these aspects to the permeation of plasma active species into the caryopses that consequently influenced metabolic processes [32]. Moreover, Zhang and Bjorn also suggested that UV radiation was a stressor that affected the content of phenolic compounds in organisms [63].

Table 5 Effect of CAPJ on the weight of fresh and dry sprout, different lowercase letters mean significant difference among different treatments at $P<0.05$ level

\begin{tabular}{lcc}
\hline Treatment time (min) & $\begin{array}{l}\text { The weight of fresh } \\
\text { sprout }(\mathrm{mg})\end{array}$ & $\begin{array}{l}\text { The weight of } \\
\text { dry sprout }(\mathrm{mg})\end{array}$ \\
\hline $0\left(\mathrm{X}_{0}\right)$ & $823.82 \pm 1.12 \mathrm{a}$ & $324.75 \pm 2.41 \mathrm{a}$ \\
$2\left(\mathrm{X}_{2}\right)$ & $1231.80 \pm 0.56 \mathrm{~b}$ & $493.73 \pm 2.19 \mathrm{~b}$ \\
$4\left(\mathrm{X}_{4}\right)$ & $1369.50 \pm 2.35 \mathrm{c}$ & $593.63 \pm 2.70 \mathrm{c}$ \\
$6\left(\mathrm{X}_{6}\right)$ & $1342.46 \pm 0.12 \mathrm{~d}$ & $525.26 \pm 3.82 \mathrm{~d}$ \\
$8\left(\mathrm{X}_{8}\right)$ & $1293.02 \pm 0.68 \mathrm{e}$ & $562.43 \pm 1.62 \mathrm{e}$ \\
$10\left(\mathrm{X}_{10}\right)$ & $1292.19 \pm 0.56 \mathrm{e}$ & $567.53 \pm 4.16 \mathrm{e}$ \\
\hline
\end{tabular}




\section{Conclusions}

A nitrogen cold atmospheric plasma jet device has been designed, constructed and operated in our laboratory. Spectroscopic measurements were performed to identify the constituent particles and estimate the rotational temperature of a nitrogen atmospheric plasma jet with a long plume. Spectroscopic measurements revealed that the particles with relatively high energy excited states exist inside the jet nozzle. The nitrogen cold atmospheric plasma jet device has been used to study the effect of non-thermal plasma on wheat seeds germination, seedling growth and vigor index. The treatment with our device did not cause any damage to the wheat seeds. The enhancement of wettability of the treated seeds can be attributed to the substantial effect of UV radiation which considered as the main component of cold atmospheric plasma. Cold atmospheric plasma plays an important role in penetrating some active compounds during the cell membrane of the wheat seeds, which leads to accelerated germination process. Under the effect of plasma generated by nitrogen cold atmospheric plasma jet not only the germination rate was stimulated, but also the vigor index of wheat. Nitrogen cold atmospheric plasma treatment leads to the dramatic effect on the seedling growth of wheat seeds. The results showed that the exposure of wheat seeds to plasma for 4 min considered the optimum condition of nitrogen cold atmospheric plasma jet treatment.

\section{References}

1. Moisan M, Barbeau J, Moreau S et al (2001) Low-temperature sterilization using gas plasmas: a review of the experiments and an analysis of the inactivation mechanisms. Int J Pharm 226(1-2):1-21

2. Liu HX, Chen JR, Yang LQ, Zhou Y (2008) Long-distance oxygen plasma sterilization: effects and mechanism. Appl Surf Sci 254:1815-1821

3. Zhang X, Huang J, Liu X et al (2009) Treatment of Streptococcus mutans bacteria by a needle plasma. J Appl Phys 105(6):063302-063307

4. Deng XT, Shi JJ, Chen HL, Kong MG (2007), Protein destruction by atmospheric pressure glow discharges. Appl Phys Lett 90(1):013903-013905

5. Ji Y-Y, Hong Y-C, Lee S-H, Kim S-D, Kim S-S (2008) Formation of super-hydrophobic and waterrepellency surface with hexamethyldisiloxane (HMDSO) coating on polyethyleneteraphtalate fiber by atmospheric pressure plasma polymerization. Surf Coat Technol 202(22-23):5663-5667

6. Shashurin A, Keidar M, Bronnikov S, Jurjus RA, Stepp MA (2008) Living tissue under treatment of cold plasma atmospheric jet. Appl Phys Lett 93(18):181501-181503

7. Hong YC, Uhm HS (2006) Microplasma jet at atmospheric pressure. Appl Phys Lett 89(22):221504-221506

8. Kolb JF, Mohamed A-AH, Price RO, Swanson RJ, Bowman A, Chiavarini RL, Stacey M, Schonenbach KH (2008) Cold Atmospheric Pressure Air Plasma Jet for Medical Applications. Appl Phys Lett 92:1-3

9. Lu X-P, Jiang Z-H, Xiong Q, Tang Z-Y, Hu X-W, Pan Y (2008) An $11 \mathrm{~cm}$ long atmospheric pressure cold plasma plume for applications of plasma medicine. Appl Phys Lett 92, Article ID: 081502

10. Hong YC, Uhm HS (2006) Microplasma jet at atmospheric pressure. Appl Phys Lett 89, Article ID: 221504

11. Zhang X, Li M, Zhou R, Feng K, Yang S (2008) Ablation of liver cancer cells in vitro by a plasma needle. Applied Phys Lett 93, Article ID: 021502

12. Hong YC, Uhm HS, Yi WJ (2008) Atmospheric pressure nitrogen plasma jet: observation of striated multilayer discharge patterns. Appl Phys Lett 93, Article ID: 051504

13. Nie Q-Y, Ren C-S, Wang D-Z, Zhang J-L (2008) A simple cold Ar plasma jet generated with a floating electrode at atmospheric pressure. Appl Phys Lett 93:011503

14. Hong YC, Cho SC, Kim JH, Uhm HS (2007) A long plasma column in a flexible tube at atmospheric pressure. Phys Plasmas 14:074502 
15. Hong YC, Cho SC, Uhm HS (2007) Twin injection-needle plasmas at atmospheric pressure. Appl Phys Lett 90:141501

16. Lotfy K (2017) Cold plasma jet construction to use in medical, biology and polymer applications. J Mod Phys 8:1901-1910

17. Park GY et al (2012) Atmospheric-pressure plasma sources for biomedical applications. Plasma Sources Sci Technol 21:043001

18. Graves DB (2012) The emerging role of reactive oxygen and nitrogen species in redox biology and some implications for plasma applications to medicine and biology. J Phys D Appl Phys 45(26):263001

19. Sreethawong T, Thakonpatthanakun P, Chavadej S (2007) Partial oxidation of methane with air for synthesis gas production in a multistage gliding arc discharge system. Int J Hydrog Energy 32:1067

20. Dobrynin D, Fridman G, Friedman G, Fridman A (2009) Physical and biological mechanisms of direct plasma interaction with living tissue. New J Phys 11:115020

21. Alves Junior C, de Oliveira Vitoriano J, da Silva DL, de Lima Farias M, de Lima Dantas NB (2016) Water uptake mechanism and germination of Erythrina velutinaseeds treated with atmospheric plasma. Sci Rep 6:33722

22. Jiang J, He X, Li L, Li JG, Shao HL, Xu QL, Ye RH, Dong YH (2014) Effect of cold plasma treatment on seed germination and growth of wheat. Plasma Sci Technol 16:54-58

23. Será B, Stranák VS, Serý M, Tichý M, Spatenka P (2008) Germination of Chenopodium album in response to microwave plasma treatment. Plasma Sci Technol 10:506

24. Será B, Gajdová I, Serý M, Spatenka P (2013) New physicochemical treatment method of poppy seeds for agriculture and food industries. Plasma Sci Technol 15:935

25. Zhou $\mathrm{R}$ et al (2016) Effects of atmospheric-pressure $\mathrm{N}_{2}, \mathrm{He}$, air, and $\mathrm{O}_{2}$ microplasmas on mung bean seed germination and seedling growth. Sci Rep 6:32603

26. Zahoranová A et al (2016) Effect of cold atmospheric pressure plasma on the wheat seedlings vigor and on the inactivation of microorganisms on the seeds surface. Plasma Chem Plasma Process 36:397

27. Dobrin D, Magureanu M, Mandache NB, Ionita MD (2015) The effect of non-thermal plasma treatment on wheat germination and early growth. Innov Food Sci Emerg Technol 29:255

28. Bormashenko E, Shapira Y, Grynyov R, Whyman G, Bormashenko Y, Drori E (2015) Interaction of cold radiofrequency plasma with seeds of beans (Phaseolus vulgaris). J Exp Bot 66:4013

29. Bormashenko E, Grynyov R, Bormashenko Y, Drori E (2012) Cold radiofrequency plasma treatment modifies wettability and germination speed of plant seeds. Sci Rep 2:741

30. Ling L, Jiangang L, Minchong S, Chunlei Z, Yuanhua D (2015) Cold plasma treatment enhances oilseed rape seed germination under drought stress. Sci Rep 4:5859

31. Denes F, Manolache S, Young RA (1999) Synthesis and surface functionalization under coldplasma conditions. J Photopolym Sci Technol 12:27-38

32. Sera B, Spatenka P, Sery M, Vrchotova N, Hruskova I (2010) Influence of plasma treatment on wheat and oat germination and early growth. IEEE Trans Plasma Sci 3:2963-2968

33. Li L, Jiang JF, Li JG, Shen MC, He X, Shao HL, Dong YH (2014) Effects of cold plasma treatment on seed germination and seedling growth of soybean. Sci Rep 4:5859-5865

34. Lotfy K (2017) Effects of cold atmospheric plasma jet treatment on the seed germination and enhancement growth of watermelon. Open J Appl Sci 7:705-719

35. Volin JC, Denes FS, Young RA, Park SMT (2000) Modification of seed germination performance through cold plasma chemistry technology. Crop Sci 40:1706-1718

36. Priestly DA, Leopold AC (1986) Alleviation of imbibitional chilling injury by use of lanolin. Crop Sci 26:1252-1254

37. Mohamed-Yasseen Y, Barringer S, Splittstoesser W, Costanza S (1994) The role of seed coats in seed viability. Bot Rev 60:426-439

38. Khan AA (1992) In: Janick J (ed) Horticultural reviews, vol 13. Wiley, Oxford

39. Kavak S, Eser B (2009) Influence of polymer coatings on water uptake and germination of onion (Allium cepa L. cv. Aki) seeds before and after storage. Sci Hortic 121:7-11

40. Deng X, Shi J, Kong MG (2006) Physical mechanisms of inactivation of Bacillus subtilis spores using cold atmospheric plasmas. IEEE Trans Plasma Sci 34:1310-1316

41. Jung H, Kim DB, Gweon B et al (2010) Enhanced inactivation of bacterial spores by atmospheric pressure plasma with catalyst $\mathrm{TiO}_{2}$. Appl Catal B 93:212-216

42. Ben Gadri R, Roth JR, Montie TC et al (2000) Sterilization and plasma processing of room temperature surfaces with a one atmosphere uniform glow discharge plasma (OAUGDP). Surf Coat Technol 131:528-541

43. Ohkawa H, Akitsu T, Tsuji M, Kimura H (2006) Pulse-modulated, high-frequency plasma sterilization at atmospheric-pressure. Surf Coat Technol 200:5829-5835 
44. Gweon B, Kim DB, Moon SY, Choe W (2009) Escherichia coli deactivation study controlling the atmospheric pressure plasma discharge conditions. Curr Appl Phys 9:625-628

45. Shirazi MU, Asif SM, Khanzada B, Khan MA, Mohammad A (2001) Growth and ion accumulation in some wheat genotypes under $\mathrm{NaCl}$ stress. Pak J Biol Sci 4:388-391

46. WFP (2013) The status of poverty and food security in Egypt: analysis and policy recommendations. http://documents.wfp.org/stellent/groups/public/documents/ena/wfp257467.pdf

47. Hatfield JL (1990) Measuring plant stress with an infrared thermometer. Hortscience 25(12):1535-1538

48. Lieberman MA, Lichtenberg AJ (2005) Principles of plasma discharges and materials processing, 2nd edn. Wiley-Interscience, Hoboken

49. Kolb JF, Mohamed A-AH, Price RO et al (2008) Cold atmospheric pressure air plasma jet for medical applications. Appl Phys Lett 92(24):241501-241503

50. Hong YC, Cho SC, Kim JH, Uhm HS (2007) A long plasma column in a flexible tube at atmospheric pressure. Phys Plasmas 14(7):074502-074505

51. Huang XJ, Xin Y, Yang L, Yuan QH, Ning ZY (2008) Spectroscopic study on rotational and vibrational temperature of $\mathrm{N} 2$ and $\mathrm{N} 2+$ in dual-frequency capacitively coupled plasma. Phys Plasmas 15(7): 113504

52. Stolarik T, Henselova M, Martinka M, Novak O, Zahoranova A, Cernak M (2015) Effect of lowtemperature plasma on the structure of seeds, growth and metabolism of endogenous phytohormones in pea (Pisum sativum L.). Plasma Chem Plasma Process 35:659-676

53. Meng Yiran, Guangzhou Qu, Wang Tiecheng, Sun Qiuhong, Liang Dongli, Shibin Hu (2017) Enhancement of germination and seedling growth of wheat seed using dielectric barrier discharge plasma with various gas sources. Plasma Chem Plasma Process 37:1105-1119

54. Filatova I, Azharonok V, Kadyrov M, Beljavsky V, Gvozdov A, Shik A, Antonuk A (2011) The effect of plasma treatment of seeds of some grains and legumes on their sowing quality and productivity. Rom J Phys 56:139-143

55. Wild S, Kesmodel LL (2001) High resolution electron energy loss spectroscopy investigation of plasma-modified polystyrene surfaces. J Vac Sci Technol 19:856-860

56. Finch-Savage WE, Leubner-Metzger G (2006) New Phytol 171:501

57. Sera B, Stranak V, Sery M et al (2008) Plasma Sci Technol 10:506

58. Sera B, Sery M, Stranak V et al (2009) Plasma Sci Technol 11:750

59. Dröge W (2002) Physiol Rev 82:47-95

60. Dhayal M, Lee SY, Park SU (2006) Using low-pressure plasma for Carthamus tinctorium L. Seed surface modification. Vacuum 80:499-506

61. Zhou ZW, Huang YF, Yang SZ, Chen W (2011) Introduction of a new atmospheric pressure plasma device and application on tomato seeds. Agric Sci 2:23-27

62. Yin MQ, Huang MJ, Ma BZ, Ma TC (2005) Stimulating effects of seed treatment by magnetized plasma on tomato growth and yield. Plasma Sci Technol 7:3143-3147

63. Zhang WJ, Bjorn LO (2009) The effect of ultraviolet radiation on the accumulation of medical compounds in plants. Fitoterapia 80:207-212

64. Grzegorzewski F, Rohn S, Kroh LW, Geyer M, Schluter O (2010) Surface morphology and chemical composition of lamb's lettuce (Valerianella locusta) after exposure to a low-pressure oxygen plasma. Food Chem 122:1145-1152

65. Matra K (2016) Non-thermal plasma germination enhancement of radish seeds. Procedia Comput Sci $86: 132-135$

66. Krentsel E, Fusselman S, Yasuda H, Yasuda T, Miyama M (1994) Penetration of plasma surface modification. 2. CF4 and C2F4 low-temperature cascade arc torch. J Polym Sci A Plasma Chem 32:1839-1845

Publisher's Note Springer Nature remains neutral with regard to jurisdictional claims in published maps and institutional affiliations. 